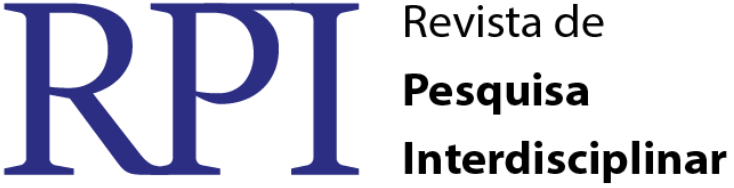

\section{A AVALIAÇÃO DO ALUNO SURDO NA ESCOLA REGULAR}

\author{
Adriana Moreira de Souza Corrêa - UFCG \\ Antonio Joamir Brito do Nascimento - SEDUC/CE \\ Maria Luana Araújo Vieira - UFCG
}

\begin{abstract}
RESUMO
A avaliação do aluno surdo é um desafio a ser superado pelas escolas brasileiras, porque implica na identificação do sistema de comunicação (Libras, Sinais Caseiros ou Língua Portuguesa), nas formas de conceber o desenvolvimento do processo de ensino-aprendizagem em um sistema unificado de avaliação, que no modelo de escola atual, está baseado na palavra escrita. Contudo, questionamo-nos qual seriam as formas mais adequadas de avaliar o aluno surdo. Diante disso, surge a necessidade de discutir a problemática que envolve a avaliação do surdo, revendo estratégias possíveis de serem aplicadas em um sistema educacional inclusivo que considerem as habilidades a serem desenvolvidas em cada etapa e a língua que servirá como mediadora neste processo. Para isso, revisitamos os documentos que norteiam o processo educacional do surdo e comparamos com a fala dos autores que trabalham a avaliação educacional e o bilinguismo, sendo estes Libâneo, Luckesi, Slomski, Skliar entre outros. Como principais resultados, verificamos que a Língua Portuguesa deve estar presente no processo de avaliação, mas que não deve ser a única forma de expressão do conhecimento utilizada e que, quando aplicada, deve considerar a escrita do Português como segunda língua. Além disso, a avaliação deve ter como objetivo identificar os erros e acertos do processo educacional, norteando as ações educativas que serão utilizadas em seguida. Consideramos ainda que para a uma avaliação estar adequada ao aluno, é necessário que esteja baseada também em estratégias mais lúdicas e interativas que possibilitem identificar compreensão dos avanços do discente em cada etapa de ensino.
\end{abstract}

Palavras-chave: Educação de surdos. Avaliação. Estratégias.

\section{EVALUATION OF THE DEAF STUDENT IN THE REGULAR SCHOOL}

\begin{abstract}
The deaf students evaluation is a challenge to be overcome by Brazilian schools, because implies the identification of communication system (Libras, Homesigns or Portuguese), at the conceiving of the development and teaching-learning process in a unified system of assessment, which in the current school model is based on the written word. However, we wonder what would be the most appropriate ways to evaluate the deaf student. Before this, there is a need to discuss the problem that involves the assessment of the deaf, reviewing possible strategies to be applied in an inclusive educational system that consider the skills to be developed at each stage and the language that will serve as a mediator in this process. For this, we revisit the documents that guide the educational process of the deaf and compared with the speech of authors that work with educational evaluation and bilingualism, which are Libâneo, Luckesi, Slomski, Skliar, among others. As the main results, we find that the Portuguese language must be present in the assessment process, but it should not be the only form of expression of knowledge used and that, when applied, must consider writing Portuguese as a second language.
\end{abstract}


Furthermore, the assessment should aim to identify the mistakes and successes of the educational process, guiding the educational actions that will be used next. We consider that to be appropriate to the student, the assessment must also be based on more playful and interactive strategies that allow identifying the understanding of the student's progress in each educational stage.

KEYWORDS: Deaf education. Assessment. Strategies.

\section{INTRODUÇÃO}

Mesmo sendo pauta de discussões por três décadas, a efetivação da proposta bilíngue para surdos no Brasil é um desafio a ser superado pelas escolas públicas. Esta proposta começou a se delinear na década de 90, em conferências mundiais que tinham como objetivo tratar da educação de todas as pessoas. Destacamos, neste movimento de repensar a educação, a participação do Brasil na Conferência Mundial da Educação Especial, organizada pela ONU, na qual foi signatário da Declaração de Salamanca (documento oriundo das discussões travadas neste evento, que teve como objetivo tratar dos princípios que viriam reafirmar a educação de todos).

O referido documento ressalta a importância de pensar em estratégias para a adaptação da escola à criança, conceituando esta ação como "pedagogia centrada na criança", indicando que cabe à este espaço social adaptar-se às necessidades e ritmos do aluno no percurso do desenvolvimento escolar. Para garantir a efetivação desta proposta, o documento define ainda que a escola precisa promover mudanças na organização do processo ensino-aprendizagem que incluam o "currículo, prédios, organização escolar, pedagogia, avaliação, pessoal, filosofia da escola e atividades extra-curriculares" (BRASIL, 1994. grifo nosso). Ao tratar especificamente da sistemática da avaliação, a declaração propõe uma reformulação neste processo, sugerindo, no ponto 29 deste documento, a implementação da avaliação formativa, por considerar que:

\footnotetext{
Avaliação formativa deveria ser incorporada no processo educacional regular no sentido de manter alunos e professores informados do controle da aprendizagem adquirida, bem como no sentido de identificar dificuldades e auxiliar os alunos a superá-las. (BRASIL, A declaração 1994, p. 4).
}

Tal proposição reforça, no sistema de avaliação, a proposta centrada no aluno e a avaliação não como fim da etapa ou nível escolar, ou seja, que serve apenas para promover ou RPI Revista de Pesquisa Interdisciplinar, Cajazeiras, v. 1, Ed. Especial, 20-29, set/dez. de 2016. 
reter o aluno, mas como uma estratégia de revisar as práticas educacionais selecionadas pelo professor.

Dois anos após a convenção, a Lei de Diretrizes e Bases da Educação Nacional, no Art. 24, inciso V, traz, como pressuposto para a avaliação do aluno, a obrigatoriedade da prevalência dos aspectos qualitativos sobre os quantitativos, bem como os resultados alcançados pelo aluno ao longo do período em oposição aos resultados atingidos apenas nos exames finais. Esta mesma lei, no Art. 59, inciso II, define a implantação da "terminalidade específica" para os alunos que, em virtude da deficiência, não puderem alcançar o nível exigido para a conclusão do ensino fundamental.

Tratando-se da educação de surdos, vemos que estes dispositivos legais trouxeram a necessidade de repensar as práticas avaliativas propostas pelos docentes ao atuarem em classes inclusivas, impondo outro desafio, que consiste definição da língua e nas estratégias selecionadas para realizar a avaliação do surdo na escola regular, que é o foco deste trabalho.

A compreensão do que significa avaliar, os tipos de avaliação e os desafios para avaliar um aluno em uma segunda língua, delineiam a construção desta pesquisa. Para isso, realizamos uma revisão bibliográfica sobre os documentos legais e as pesquisas que tratam sobre a temática.

\section{Identificando o aluno surdo}

Apesar da Declaração de Salamanca, desde 1994, recomendar que educação da pessoa surda considerasse a Língua de Sinais Nacional (que nesse documento é denominado Língua Nacional de Signos), no Brasil, o reconhecimento legal da Língua

Sinais aconteceu apenas em 2002, com a lei $\mathrm{n}^{\mathbf{0}}$ 10.436/2002. A aprovação deste dispositivo legal se constituiu em um passo importante para a discussão do processo educacional da pessoa surda, pois, na regulamentação desta lei, pelo Decreto $n^{\circ} 5.626 / 2005$, foram esclarecidos muitos pontos referentes às práticas e adaptações que garantirão o acesso e a permanência do aluno surdo na escola.

Tanto na lei, como no decreto, vemos ser reafirmada que o surdo é aquele que desenvolveu uma compreensão primordialmente visual do mundo, ou seja, que se comunica por um sistema visual espacial. Na Lei da Libras, no parágrafo único, Art. $1^{\circ}$, esta língua é definida como um: 
[...] sistema linguístico de natureza visual-motora, com estrutura gramatical própria, constituem um sistema linguístico de transmissão de ideias e fatos, oriundos de comunidades de pessoas surdas do Brasil (BRASIL, 2002).

Já o Decreto, citado anteriormente, no Art. $2^{\circ}$, caracteriza a pessoa surda como "aquela que, por ter perda auditiva, compreende e interage com o mundo por meio de experiências visuais, manifestando sua cultura principalmente pelo uso da Língua Brasileira de Sinais Libras". Vemos assim, que a condição da perda da audição não é suficiente para definir a pessoa surda, mas a sua opção linguística. Caso o aluno optasse pela comunicação através da fala, ele seria definido como deficiente auditivo.

Tanto o Decreto 5.626, no Art. 16, como a Declaração de Salamanca, o uso da Língua de Sinais ou da oralidade, pelo surdo é uma opção que deve ser definida pela família e pelo próprio surdo (caso este tenha condições de decidir pelo sistema de comunicação que irá utilizar). Diante da permissão legal para a realização desta escolha, cabe a escola identificar os mecanismos de divulgação da Libras, possibilitando ainda, que as avaliações ocorram nesta língua. Todavia, não podemos nos esquecer que cerca de $95 \%$ dos nascem em famílias nas quais os pais são ouvintes (SLOMSKI, 2010) gerando tensões sobre a língua que o aluno é capaz de apresentar maior desempenho acadêmico e aquela que a família do discente irá optar. Sobre a relação entre o uso da língua e o aprendizado do aluno surdo, vemos que:

Muitos pais ouvintes - devido à sugestão de certos profissionais clínicoterapêuticos e por falsas representações sociais - tendem a condicionar o contato comunicativo com os seus filhos surdos à aparição de respostas auditivas e orais e não dão atenção aos indícios de comunicação visual. [...] Entretanto, é difícil imaginar que os pais ouvintes que não aceitam a Língua de Sinais renunciem a toda forma de comunicação com seus filhos surdos, por isso, independente do sigilo e controle de certos profissionais, muitos pais criaram um sistema de comunicação gestual com seus filhos surdos (SKLIAR, 2001, p. 132).

O sistema de comunicação criado pela família, como podemos observar, difere-se da Libras e não se constitui uma língua. Esta forma de interação, chama-se sinais caseiros ou homesigns e são definidos por Morford (1996, citado por TEIXEIRA e CERQUEIRA, 2014) como sinais estruturados sem a influência da fala e, por esta razão, apresentam similaridade com a Língua de Sinais. Entretanto, eles apresentam, uma estrutura simplificada, baseada em generalizações através de gestos dêiticos e icônicos.

Vemos assim que os alunos usuários de sinais caseiros encontram, na proposta inclusiva, uma alternativa para o aprendizado da Língua de Sinais na escola. Ainda que o RPI Revista de Pesquisa Interdisciplinar, Cajazeiras, v. 1, Ed. Especial, 20-29, set/dez. de 2016. 
aluno surdo tenha, na classe ou na escola, a companhia de usuários da Libras que o possibilitem a aquisição contextualizada da Língua de Sinais, o processo de externalização dos conhecimentos adquiridos por meio da Libras ou em Língua Portuguesa não será imediata, ou seja, o aluno necessitará de estratégias de avaliação diferenciadas para expressar os conhecimentos do conteúdo no decorrer deste processo.

Após diferenciar o aluno surdo daquele que apresenta a deficiência auditiva, veremos como a legislação orienta que seja realizada a avaliação do usuário da Libras.

\section{A Avaliação Na Escola Regular}

Antes de tratarmos da educação do aluno surdo, faz-se necessário definir o processo de avaliação e quais variações este pode apresentar. Precisamos, inicialmente, desmitificar a ideia arraigada no nosso sistema educacional de que a avaliação tem como objetivo apenas a promoção ou reprovação do aluno em uma etapa da educação. Corroboramos com a provocação de Luckesi (1998) no artigo "Avaliação da aprendizagem escolar: apontamentos da pedagogia do exame”, escrito em 1991, ao ressaltar que a há uma exacerbada preocupação na promoção do aluno em detrimento à compreensão do processo de aprendizagem, como construção do conhecimento. $\mathrm{O}$ autor diferencia ainda a verificação e a avaliação escolar afirmando que, enquanto a primeira visa quantificar o conhecimento do aluno, tendo um fim em si mesma e servindo como objetivo a aprovação ou reprovação; a segunda busca ressignificar a ação do aluno e do docente no processo ensino-aprendizagem.

Libâneo (2007), corroborando com Luckesi, afirma que a avaliação escolar como um momento do processo ensino-aprendizagem que tem como objetivo verificar a compreensão do aluno sobre o que foi proposto e orientar o docente na seleção das atividades didáticas que seguirão este momento. Este autor acrescenta que a avaliação deve acontecer em três etapas, sendo estas: a verificação, que se refere ao procedimento de coleta de dados; a qualificação, que é a comprovação dos resultados obtidos em função dos objetivos que foram propostos; e a apreciação qualitativa que indica os resultados encontrados em comparação aos desempenhos esperados. Como vimos, a avaliação não finaliza na apreciação qualitativa, ao contrário, ela servirá para delinear os novos caminhos a serem trilhados rumo ao conhecimento, verificando as estratégias educacionais que apresentaram melhores resultados com o grupo.

RPI Revista de Pesquisa Interdisciplinar, Cajazeiras, v. 1, Ed. Especial, 20-29, set/dez. de 2016. 
No entanto, devemos estar atentos para o fato que o processo educacional e de avalição não deve estar focado apenas na compreensão dos conteúdos, mas deve inserir habilidades que permitam o desenvolvimento pleno do aluno. Delors et. al. (1999), que a educação deve se pautar em quatro princípios, sendo eles: aprender a conhecer (ou aprender a aprender, que significa identificar as estratégias de acesso ao conhecimento), aprender a fazer (para utilizar o conhecimento para agir no mundo), aprender a conviver (que é a consciência da força da ação cooperativa e do papel do outro na construção social) e aprender a ser (buscando desenvolver a autonomia, a percepção e a responsabilidade social).

Sabemos que o nosso sistema é permeado pela avaliação escrita e individual, mas isso não significa que o aluno deva demonstrar seus conhecimentos escolares somente desta forma. Diante das habilidades apresentadas pelo autor, precisamos considerar outras formas de avalia-las tendo em vista que favorecem não só o desenvolvimento acadêmico, mas favorecem a inserção crítica e ativa no meio social.

Delors et. al.(2010), ao tratar da constituição do sujeito diante da ação educativa acrescenta que "a educação deve levar em consideração todas as potencialidades de cada indivíduo: memória, raciocínio, sentido estético, capacidades físicas, aptidão para comunicarse". Neste mesmo documento, os autores identificam a educação não pode ser um instrumento de exclusão social e, por isso, constatamos que a educação também precisa buscar formas de fazer com que o surdo seja capaz de desenvolver as habilidades elencadas anteriormente, de forma a favorecer a sua intervenção na realidade em que vive. Neste sentido, o conhecimento trabalhado na escola, precisa ser avaliado por outro viés a fim de possibilitar o desenvolvimento holístico do indivíduo.

\section{Avaliação Educacional Do Surdo: Inclusão Ou Exclusão}

Observamos que, por ser o surdo um indivíduo essencialmente visual, a Língua de Sinais é a única língua possível de ser adquirida naturalmente, em contextos reais de uso, e, por esta razão, se configura na forma de comunicação na qual o surdo tem aptidão para a comunicação, em função do seu aparato biológico (SLOMSKI, 2010). Já a Língua Portuguesa, que é a língua majoritária, se configura em um sistema linguístico que apresenta modalidades de produção e recepção diferenciadas da sua língua natural, necessitando de intervenções planejadas para o seu aprendizado (CHOI et. al, 2011).

RPI Revista de Pesquisa Interdisciplinar, Cajazeiras, v. 1, Ed. Especial, 20-29, set/dez. de 2016. 
Ao revisitarmos a lei da Libras, vemos que no parágrafo único do art. $4^{\circ}$, que a Língua Portuguesa, na modalidade escrita, não pode ser substituída pela Libras. Diante disso, muitos professores podem se apoiar neste artigo para permanecerem com as avaliações que priorizam a Língua Portuguesa. No entanto, ao utilizar estas práticas, devemos considerar que o aluno surdo não estará sendo adequadamente avaliado, pois, ao passo que os ouvintes são avaliados na sua primeira língua, a maioria dos surdos é avaliada na segunda língua, sendo esta a que eles apresentam desempenho inferior quando comparados à sua primeira língua. Slomski (2010), ao tratar da educação inclusiva, afirma que a opção pela língua na qual deve ocorrer a avaliação deve estar centrada nas possibilidades do aluno, utilizando o idioma que ele prefere e que a estratégia de avaliação deve adequar-se às possibilidades de produção em primeira ou em segunda língua.

O Decreto 5.626/2005, cap. IV, afirma que o sistema de ensino deve utilizar mecanismos que favoreçam a avaliação do surdo em decorrência de um aprendizado de segunda língua, ou seja, a correção das respostas á questões e textos devem valorizar a ideia, o aspecto semântico, em detrimento à organização das sentenças na ordem formal da Língua Portuguesa. Ainda no decreto, garante que o professor pode utilizar meios de avaliação alternativos, tendo a Libras a língua de expressão desde que registrados em vídeo ou outros recursos eletrônicos ou tecnológicos (BRASIL, 2005).

Vemos assim que há previsão legal para a avaliação do surdo tanto em Língua de Sinais quanto em Língua Portuguesa. Entretanto, devemos ter em mente que o surdo passará por estágios de interlíngua antes de conseguir expor, claramente o conhecimento através do Português. Sobre a interlíngua do surdo, acreditamos que:

[...] cada professor, após aprimorar seus conhecimentos, inteirando-se do que é e como ocorre o processo avaliação escolar do aluno surdo, deve embasar suas práticas avaliativas no entendimento de que a aprendizagem não é um processo passivo e mecânico, mas ativo, em que os alunos surdos apresentarão vários estágios de aquisição tanto da LIBRAS quanto da Língua Portuguesa, ou seja, seus textos vão se modificando e, progressivamente, suas características não mais representam a língua 1 ou língua base, que seria LIBRAS, mas ainda não representam a língua 2 , que seria Língua Portuguesa (MAHL; RIBAS, 2013).

Assim, não estamos afirmando que o professor deva abolir a Língua portuguesa das avaliações, mas que este processo também seja mediado por outras estratégias que visem mostrar o grau de apreensão do conhecimento deste aluno, não só referente ao conteúdo, como também, diante das habilidades indicadas por Delors, que favoreçam a sua inserção RPI Revista de Pesquisa Interdisciplinar, Cajazeiras, v. 1, Ed. Especial, 20-29, set/dez. de 2016. 
social. Também não somos a favor do retorno da filosofia educacional da Comunicação Total, na qual a leitura orofacial, alfabeto manual, fala e outras estratégias serviam como suporte de aprendizado da fala, mas que o professor identifique a construção do conhecimento que ocorre em sala de aula, tendo como instrumento a produção de glossários, de vídeos, de peças teatrais, bem como outros recursos lúdicos que favoreçam a expressão das diferentes habilidades que favorecem a inserção social do sujeito surdo. Estas estratégias são significativas e aproximam-se às situações nas quais os indivíduos surdos, e também os ouvintes que partilham este momento de aprendizagem.

\section{Considerações Finais}

A avaliação escolar da pessoa surda é um tema que necessita de mais discussões, tendo em vista que, apesar de partilhar a Língua de Sinais, os surdos apresentam características diferenciadas. Independente do grau de surdez, todas as pessoas apresentam habilidades que devem ser valorizadas e estas, nem sempre são mediadas pela palavra. Vemos assim que, antes de selecionarmos a estratégia avaliativa mais adequada ao aluno, devemos considerar que a língua que este se sente mais confortável para expressar o conhecimento, além de buscar estratégias que avaliem outras habilidades a serem desenvolvidas na escola.

Para que haja esta mudança na percepção da avaliação, faz-se necessário ressignificála e percebê-la forma de identificar o avanço conquistado a cada etapa de aprendizagem e que, para isso, podemos recorrer ao lúdico e à identificação do aluno no processo e não só ao fim de cada etapa.

Diante disso, a escola que pretende formar cidadãos críticos e inserir os surdos, não pode mais se basear apenas em textos, mas buscar estratégias de aprendizagem e de avaliação nas quais todos os alunos sejam capazes de expressar criticamente o conhecimento. Alguns discentes farão isso pela palavra escrita, outros pela Libras, há ainda aqueles que terão a habilidade de transformar este conhecimento em música, poesia, teatro, pesquisa e outros e que, cabe ao professor garantir que diferentes formas de expressão do conhecimento sejam reconhecidas no espaço escolar.

Acreditamos que esta mudança visa favorecer não só aos alunos surdos, como também possibilita o reconhecimento de habilidades que, muitas vezes, são desconhecidas ou desvalorizadas no ambiente escolar, sendo produtivas também, para a apropriação do conhecimento não só dos alunos surdos como dos ouvintes. 


\section{REFERÊNCIAS}

BRASIL. Lei de Diretrizes e Bases da Educação Nacional, de 20 de dezembro de 1996.

BRASIL. Lei $\mathbf{n}^{\mathbf{0}} \mathbf{1 0 . 4 3 6}$, de 24 de abril de 2002.

BRASIL. Decreto no 5.626, de 22 de dezembro de 2005 .

BRASIL. Declaração de Salamanca. Brasília: UNESCO, 1998.

CHOI, D. et. al.; PEREIRA, M.C. C.(Org.). Libras: conhecimento além dos sinais. $1^{\text {a }}$ ed. São Paulo: Pearson Prentice Hall, 2011.

DELORS, J. et. al. Educação: um tesouro a descobrir. Trad. Guilherme Teixeira. Brasília: UNESCO, 2010.

LIBÂNEO, J. C. Didática. 1 $1^{\text {a }}$ ed. São Paulo: Cortez,1990.

LUCKESI, C. C. Avaliação da aprendizagem escolar. 7ª ed. São Paulo: Cortez, 1998.

MAHL, E. RIBAS, V. A. Avaliação escolar para alunos surdos: entendimentos dos professores sobre este processo. In. Congresso Brasileiro Multidisciplinar de Educação Especial. 7. 2013. Londrina. Resumos.Londrina. Hotel Sumatra. Disponível em: < http://www.uel.br/eventos/congressomultidisciplinar/>. Acesso em: 01 set. 2016.

SKLIAR, C. A perspectiva sócio-histórica sobre a psicologia e a educação de surdos. In. Educação \& Exclusão. $3^{\text {a }}$ ed. Porto Alegre: Mediação, 2001.

SLOMSKI, V. G. Educação Bilíngue para Surdos: concepções, implicações e práticas. Curitiba: Juruá, 2010.

TEIXEIRA, E. R.; CERQUEIRA, I. F. Sinais caseiros: ponto de partida para o letramento de crianças surdas e consequente aquisição de Libras e português escrito como L2. In. SIELP - simpósio internacional de ensino de Língua Portuguesa. Vol 3., n. 1, 2014, Uberlândia (anais) Disponível em: <http://www.ileel.ufu.br/anaisdosielp/wpcontent/uploads/2014/11/535.pdf>. Acesso em: 23 ago. 2016.

RPI Revista de Pesquisa Interdisciplinar, Cajazeiras, v. 1, Ed. Especial, 20-29, set/dez. de 2016. 